2. Hayes CG, Phillips IA, Callahan JD, Griebenow WF, Hyams KC, Wu SJ, et al. The epidemiology of dengue virus infection among urban, jungle, and rural populations in the Amazon region of Peru. Am J Trop Med Hyg. 1996;55(4):459-63.

3. Kochel TJ, Aguilar P, Felices V, Comach G, Cruz C. Molecular epidemiology of dengue virus type 3 in Northern South America: 2000-2005. Infect Genet Evol. 2008;8:682-8.

4. Forshey BM, Morrison AC, Cruz C, Rocha C, Vilcarromero S, Guevara C, et al. Dengue virus serotype 4, northeastern Peru, 2008. Emerg Infect Dis. 2009;15(11):1815-8.

5. World Health Organization. Dengue. Guidelines for diagnosis, treatment, prevention and control. 2009.

6. Morrison AC, Minnick SL, Rocha C, Forshey BM, Stoddard $\mathrm{ST}$, Getis A, et al. Epidemiology of dengue virus in lquitos, Peru 1999 to 2005: interepidemic and epidemic patterns of transmission. PLoS Negl Trop Dis. 2010;4(5):e670.

Correspondencia: Salomón Durand Velazco.

Dirección: Jr. Callao 377 Iquitos Perú.

Teléfono: 51 965-618018

Correco electrónico: sdurandv@yahoo.com,

salomon.durand@gmail.com

\section{LARVAS DE Strongyloides spp. EN LECHUGAS OBTENIDAS EN MERCADOS DE LIMA}

\section{[Strongyloides spp. LARVAE IN LETTUCES OBTAINED IN MARKETS OF LIMA]}

\author{
César Guerrero Barrantes ${ }^{1}$ a, \\ Amparo Garay Bambarén ${ }^{1,2}$ b, Alfredo Guillén 1, 3 c
}

Sr. Editor: La creciente preocupación acerca de la transmisión de microorganismos patógenos por los alimentos, lleva a una necesidad de controlar toda la cadena alimentaria, desde el producto primario hasta el consumidor (1). En la industria alimentaria son cada vez más conscientes de la posibilidad de contaminación de sus productos con protozoos y estadios de helmintos y platelmintos; estos parásitos se han convertido en riesgos para la salud pública y en una preocupación para quienes trabajan en la comercialización de alimentos.

Los productos frescos, en particular la lechuga, son consumidos con una preparación mínima y, al ser empleadas crudas en las ensaladas, son un vehículo

\footnotetext{
Facultad de Tecnología Médica, Universidad Nacional Federico Villarreal. Lima, Perú.

2 Hospital Central de las Fuerzas Policiales Luis N. Saenz. Lima, Perú.

3 Clínica San Borja, Lima, Perú.

a Biólogo-Microbiólogo, Profesor Principal FTM-UNFV; b Tecnólogo Médico; ' Médico Microbiólogo.
}

$$
\text { Recibido: 28-01-11 Aprobado: 02-02-11 }
$$

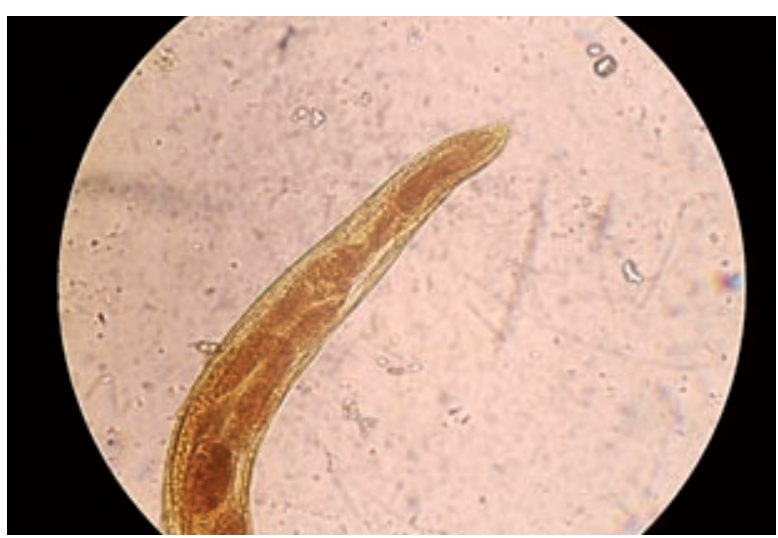

Figura 1. Larva rabditoidea de Strongyloides spp. parte anterior. Preparado con Lugol (400x).

potencial de transmisión. El agua de riego contaminada, en particular, constituye una vía importante de contaminación para los productos frescos ${ }^{(2)}$. La lechuga, de elevada demanda de consumo por nuestra población, es susceptible de contaminación, ya que es producida, cosechada y transportada, por lo general, artesanalmente. La detección fiable de organismos patógenos en los productos alimenticios y el seguimiento de estos ayudará a la prevención de brotes de enfermedades parasitarias asociadas con los alimentos contaminados.

Se evaluaron 60 muestras de lechugas, tomadas al azar simple desde tres puestos de venta por visita, en los mercados de La Parada (La Victoria) y Caquetá (San Martín), desde marzo a mayo de 2010 para la búsqueda de enteroparásitos entre protozoos y helmintos. Usando guantes, cuidadosamente, deshojamos la cabeza de lechuga, eliminando las hojas externas marchitas o maltratadas; las hojas seleccionadas fueron colocadas en una bolsa plástica estéril hasta alcanzar el peso de $50 \mathrm{~g}$, a ello se añadió inmediatamente, poco a poco, $250 \mathrm{~mL}$ de solución salina fisiológica $(0,85 \%)$, luego el contenido se agitó por treinta minutos.

Seguidamente, se procedió a filtrar el contenido a través de una capa de gasa doble y colador o tamiz, en un vaso de precipitados de $500 \mathrm{~mL}$. El filtrado obtenido se centrifugó a 3000 r.p.m por $10 \mathrm{~min}$, en tubos de polipropileno de $50 \mathrm{~mL}$, se repitió el procedimiento hasta que el sobrenadante quedó claro. El sedimento obtenido fue observado microscópicamente, con objetivo de 400x; se colocó dos gotas, separadas del sedimento sobre una lámina portaobjeto y se añadió a una de ellas una gota de solución de lugol y a la otra una gota de azul de metileno, luego se les colocó una lámina cubreobjetos.

De las 60 muestras de lechuga evaluadas, 38 (63,3\%) presentaron contaminación con larvas de Strongyloides 


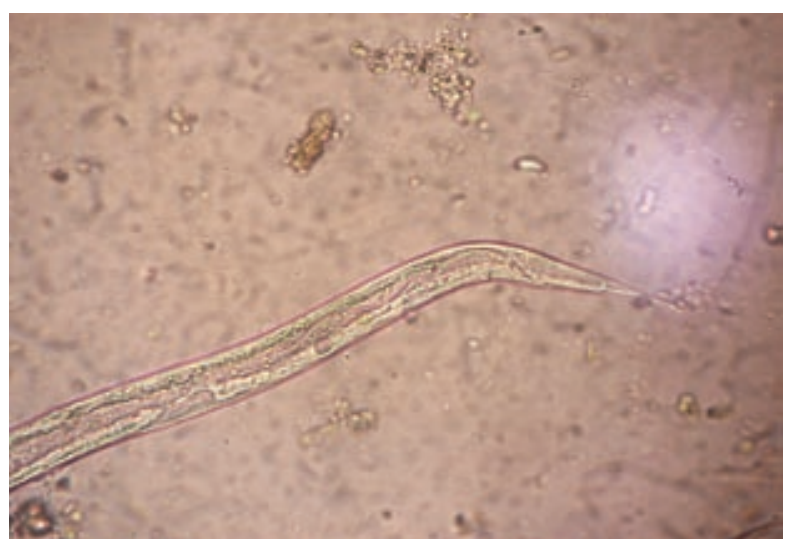

Figura 2. Larva Filariforme de Strongyloides spp. Extracto de lavado de lechuga con SSF (400x).

spp., en fases de larvas filariforme y rabditoide (Figuras 1 y 2), este fue el enteroparásito detectado con más frecuencia entre los protozoos y helmintos.

Estos hallazgos, son los primeros reportados en nuestro medio, y muestran un elevado porcentaje de detección comparado con los estudios realizados en mercados populares de Venezuela, por Rivero y et al. (3), en Maracaibo (40\%); por Traviezo-Valles ${ }^{(4)}$, en Lara con el $16 \%$ y por Devera y et al. ${ }^{(5)}$, en el Estado de Bolívar $(15,7 \%)$; mientras que en los mercados de Corrientes, Argentina ${ }^{(6)}$, se reporta un nivel sumamente bajo $(2 \%)$ de lechugas contaminadas por larvas de Strongyloides.

La elevada contaminación de este vegetal con enteroparásitos, obedece a que son regadas con aguas servidas o aguas contaminadas con restos fecales. A ello también contribuye el hecho que, muchas veces, los campos de cultivo son abonados con estiércol y materia orgánica de origen fecal (compost y restos de heces de ganado). La presencia de las larvas, tanto

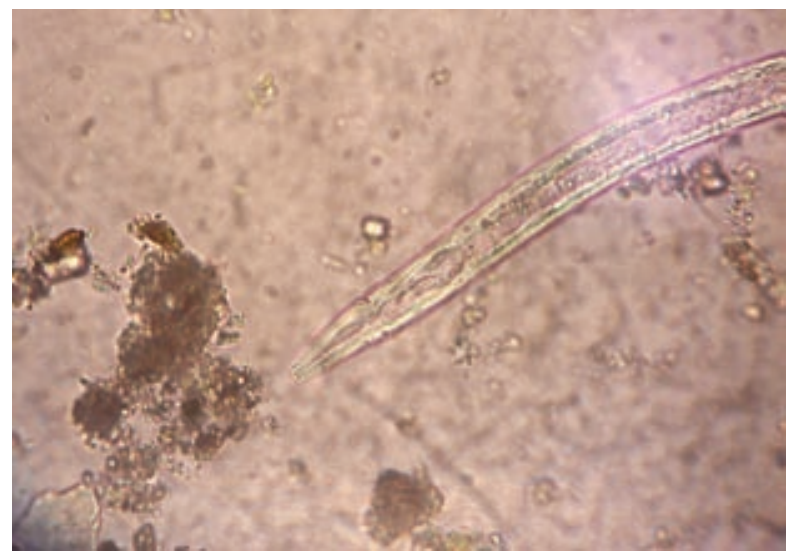

Figura 3. Larva Rabditoidea de Strongyloides spp. parte anterior, nótese el esófago. Extracto de lavado de lechuga con SSF (400x). rhabditoides como filariformes, pueden pertenecer a las formas larvarias de fitoparásitos o de vida libre, sin embargo, es prudente mantener en consideración la posibilidad del riesgo que sean parásitos infectantes para el hombre.

\section{AGRADECIMIENTOS}

Agradecemos la colaboración de los señores: Alarcón Baldeón J.J.; Carrillo Yaga M.L.;Gonzales Herrera R.J.; Juliachs Cárdenas M.S.; Pantoja Mendoza M.; Pulido Colina A.; Rivera Díaz I.D. y Soto Valdez M.C. de la facultad de Tecnologìa Médica UNFV.

\section{Conflictos de Interés}

Los autores declaran no tener conflictos de interés en la publicación del presente artículo.

\section{REFERENCIAS BIBLIOGRÁFICAS}

1. Smith HV, Nichols RA. Zoonotic protozoa - food for thought. Parasitologia 2006, 48:101-104

2. Chaidez C, Soto M, Gortares P, Mena K. Occurrence of Cryptosporidium and Giardia in irrigation water and its impact on the fresh produce industry. Int. J. Environ. Health Res. 2005, 15:339-345.

3. Rivero de Rodríguez Z, Fonseca R, Moreno Y, Oroño I, Urdaneta M. Detección de parásitos en lechugas distribuidas en mercados populares del municipio de Maracaibo, Venezuela. Kasmera. 1998, 26:1-21

4. Traviezo-Valles L, Dávila J, Rodríguez R, Perdomo O, Pérez J. Contaminación enteroparasitaria de lechugas expendidas en mercados del estado Lara. Venezuela. Parasitol Latinoam 2004, 59: 167 - 170.

5. Devera R, Blanco Y, González H, García L. Parásitos intestinales en lechugas comercializadas en mercados populares y supermercados de Ciudad Bolívar, Estado Bolívar, Venezuela Rev. Soc. Ven. Microbiol. 2006, 26(2): 32-38.

6. Rea MJ, Fleitas A, Borda CE. Existencia de parásitos intestinales en hortalizas que se comercializan en la ciudad de Corrientes, Argentina. Ciorrientes: Universidad Nacional del Nord este; 2004.

Correspondencia: Blgo. Cesar Guerrero Barrantes Facultad de Tecnología Médica. -UNFV, El Agustino, Lima.

Teléfono:01 362-7477.

Correo electrónico: cesgueba@ec-red.com

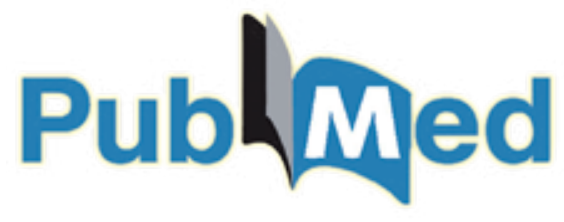

